\title{
Pelatihan Budidaya Tanaman Aren untuk Meningkatkan Kapasitas Masyarakat Desa Lubuk Ogung Kecamatan Bandar Sei Kijang Kabupaten Pelalawan Provinsi Riau
}

\section{Palm Sugar Cultivation Training to Increase Community Capacity in Lubuk Ogung Village, Bandar Sei Kijang District, Pelalawan Regency, Riau Province}

\begin{tabular}{|c|}
\hline Yeni Kusumawaty ${ }^{1^{*}}$ \\
\hline Roza Yulida ${ }^{1}$ \\
\hline Tengku Harunur Rasyid ${ }^{2}$ \\
\hline Armaini 1 \\
\hline Evy Maharani 1 \\
\hline Susy Edwina ${ }^{1}$ \\
\hline Rahmayuni ${ }^{1}$ \\
\hline $\begin{array}{l}\text { 1Universitas Riau, Pekanbaru, Riau, } \\
\text { Indonesia }\end{array}$ \\
\hline $\begin{array}{l}\text { Balai Penelitian dan Pengembangan } \\
\text { Provinsi Riau, Pekanbaru, Riau, } \\
\text { Indonesia }\end{array}$ \\
\hline $\begin{array}{l}\text { "email: } \\
\text { yeni.kusumawaty@lecturer.unri.ac.id }\end{array}$ \\
\hline $\begin{array}{l}\text { Kata Kunci } \\
\text { Aren } \\
\text { Budidaya } \\
\text { Pembibitan } \\
\text { Benih } \\
\text { Bina Desa }\end{array}$ \\
\hline $\begin{array}{l}\text { Keywords: } \\
\text { Arenga sugar palm } \\
\text { Cultivation } \\
\text { Nursery } \\
\text { Seed } \\
\text { Village development }\end{array}$ \\
\hline $\begin{array}{l}\text { Received: October } 2019 \\
\text { Accepted: December } 2019 \\
\text { Published: March } 2020\end{array}$ \\
\hline
\end{tabular}

\begin{abstract}
Abstrak
Di Provinsi Riau, sebagian besar usaha tani masyarakat adalah berkebun sawit. Namun saat ini, mekanisme pasar menyebabkan harga sawit yang dibeli dari penduduk menjadi sangat rendah. Di Desa Kiyap Jaya Kecamatan Bandar Sei Kijang telah dimulai penanaman pohon aren di sela tanaman sawit yang dirintis oleh salah seorang petani sawit. Lokasi di Desa Lubuk Ogung yang bersebelahan dengan Desa Kiyap Jaya dan belum melakukan budidaya tanaman aren untuk mengembangkan sentra aren di Desa Lubuk Ogung. Masyarakat sasaran dari kegiatan bina desa ini adalah warga desa termasuk petani kelapa sawit skala kecil yang memiliki lahan kebun sawit atau lahan pekarangan. Kegiatan pengabdian terdiri dari kontak aparat desa dan persiapan materi; persiapan Sumber Daya Manusia dengan pembentukan 4 kelompok tani aren; alokasi lahan; pelatihan teori dan praktek teknis pembibitan dan budidaya tanaman aren dan kegiatan persemaian dan pembenihan dan penanaman bibit aren di lokasi lahan yang telah dipersiapkan. Manfaat kegiatan adalah petani memahami prospek ekonomi produk aren yang sangat tinggi sehingga memiliki motivasi untuk menekuni pembibitan dan penanaman aren, petani memiliki kemampuan dalam pembibitan dan budidaya tanaman aren, dan petani melaksanakan praktek penyemaian biji secara berkelompok menjadi anakan aren berkualitas dan bernilai ekonomis.
\end{abstract}

\begin{abstract}
In Riau Province, the majority of community farming is oil palm gardening. But at present, the market mechanism causes the price of palm oil purchased from the population to be very low. In the Village of Kiyap Jaya, Bandar Sei Kijang District, planting of palm trees has begun in between the oil palm plants which were pioneered by one of the oil palm farmers. The location is in Lubuk Ogung Village, which is adjacent to Kiyap Jaya Village and has not yet cultivated sugar palm plants to develop sugar palm centers in Lubuk Ogung Village. The target communities of village development activities are villagers including small-scale oil palm farmers who own oil palm or yard plots. Community service activities consist of contacting village officials and material preparation; preparation of Human Resources with the formation of four groups of sugar palm farmers; land allocation; theoretical training and technical practice of seedling and cultivation of palm trees and nursery and hatchery activities and planting of palm seeds in the prepared land location. The benefit of the activity is that the farmer understands the economic prospects of sugar palm products that are very high so that they have the motivation to pursue sugar palm seedlings and planting; farmers have the ability to breed and cultivate sugar palm plants, and the farmers carry out the practice of seed seeding in groups to become high quality and economically valuable palm saplings.
\end{abstract} Palangkaraya. This is Open Access article under the CC-BY-SA License (http://creativecommons.org/licenses/by-sa/4.0/). DOI: https://doi.org/10.33084/pengabdianmu.v5i2.1041 


\section{PENDAHULUAN}

Di Provinsi Riau, hampir sebagian besar usaha tani masyarakat adalah berkebun sawit. Namun saat ini, mekanisme pasar menyebabkan harga sawit yang dibeli dari penduduk menjadi sangat murah. Hal ini berimbas pada perekonomian makro masyarakat. Mayoritas masyarakat desa di Kecamatan Bandar Sei Kijang Kabupaten Pelalawan memiliki kebun kelapa sawit skala kecil. Penurunan harga kelapa sawit akhir-akhir ini mendorong masyarakat di sentra-sentra perkebunan kelapa sawit untuk mencari alternatif pemasukan lain. Untuk memperkuat kondisi perekonomian masyarakat, salah satunya adalah dengan menanam aren di sela-sela tanaman sawit, agar nilai ekonomi lahan semakin bertambah (Pohan, 2015).

Tanaman aren telah lama dikenal walaupun belum umum dibudidayakan. Hal ini disebabkan tanaman aren baru memproduksi nira pada umur 10-12 tahun yang kurang menarik bagi masyarakat untuk membudidayakannya karena dianggap terlalu lama (Febriyanti et al., 2017). Tetapi selain aren tipe Dalam ini, eksplorasi di Pulau Kalimantan pada tahun 2009 menemukan tanaman aren tipe genjah yang dapat berproduksi pada umur 5 tahun. Tipe aren genjah Kutai Timur memiliki produktivitas cukup tinggi dengan hasil nira > 12 liter/hari/ mayang dan lamanya waktu penyadapan > 2,5 bulan/mayang (Tenda et al., 2011).

Tanaman aren merupakan tanaman yang lebih produktif jika ditanam sebagai tanaman sela (system mixcropping) diantaranya dengan penanaman di antara pohon kelapa sawit. Pohon aren dapat ditumpangsarikan dan hidup berdampingan dengan pohon lain (Bernhard, 2007). Aren dapat bertumbuh subur di tengah perkebunan kopi, atau diselilingi pohon kayu hutan, tanaman buah yang sekaligus untuk tujuan investasi. Aren yang dikombinasikan dengan tanaman kayu hutan atau buah dapat dianggap sebagai tanaman investasi.

Pohon aren dapat dikatakan tanaman perkebunan multiguna karena dimanfaatkan, baik berfungsi sebagai konservasi, maupun fungsi produksi yang menghasilkan berbagai komoditi bernilai ekonomi (Alam \& Baco, 2004). Fungsi konservasi lahan terjadi karena perakarannya yang melebar yang mencegah erosi tanah. Daun yang cukup lebat dan batang yang tertutup dengan lapisan ijuk efektif untuk menahan kekuatan air hujan yang langsung ke permukaan tanah. Keuntungan lain tanaman aren tidak membutuhkan pemupukan intensif dan tidak mengharuskan penggunaan pestisida sehingga aman bagi lingkungan (Efendi, 2010).

Masyarakat setempat mengumpulkan nira aren dengan mengetuk dan menyadap bunga aren jantan. Aktivitas menyadap nira aren hanya dilakukan oleh laki-laki karena membutuhkan keterampilan memanjat pohon menggunakan tangga bambu dan keberanian untuk menggantung di pohon yang tinggi. Adapun pengolahan produk aren lain seperti kolang-kaling, sapu ijuk dan sapu lidi, umumnya dilakukan oleh pria dan wanita (Azhar et. al, 2019).

Tanaman aren adalah salah satu jenis palma yang penyebarannya sangat luas di Indonesia (Tenda et al., 2008). Dalam data Direktorat Jenderal Perkebunan Kementerian Pertanian pada 2006, dalam kurun waktu 5 tahun (2001-2005) areal tanaman aren mengalami fluktuasi, yaitu dari luas 44.857 ha pada tahun 2001, terakhir menjadi 59.504 ha pada tahun 2005 dengan produksi sebesar 33.498 ton pada tahun 2001 dan 49.319 ha pada tahun 2005. Walaupun saat ini sudah ada beberapa daerah yang mulai membudidayakan tanaman aren, tapi umumnya tanaman aren masih tumbuh secara liar (Tenda et al., 2011). 
Sejalan dengan ini, Mariati (2013) menyatakan bahwa permasalahan terkait tanaman aren yang dihadapi secara umum di Indonesia saat ini adalah keberadaan tanaman aren umumnya belum dibudidayakan secara baik, masih mengandalkan pertumbuhan secara alami dan banyak areal pertanaman aren yang sudah beralih fungsi dengan tanaman lain atau pemukiman. Di lokasi Desa Kiyap Jaya, nira aren yang telah dihasilkan dijual langsung sebagai minuman segar dan dicampur dengan kopi menjadi produk kopi nira. Tetapi jumlah tanaman aren masih terbatas dan belum mampu memenuhi permintaan pasar yang sangat tinggi, hasil nira bervariasi karena bibit yang digunakan bukan bibit unggul dan letaknya tersebar karena belum dibudidayakan. Kebutuhan yang paling mendesak saat ini adalah pelaksananaan budidaya tanaman aren (Fatah \& Sutejo, 2015).

Terkait dengan hal tersebut penyediaan benih bermutu yang berasal dari pohon-pohon aren berproduksi tinggi sangat dibutuhkan. Masyarakat Desa Lubuk Ogung dapat melihat tingginya permintaan akan nira segar dan berminat untuk ikut melakukan budidaya aren. Maka diperlukan kegiatan pelatihan bagi masyarakat Desa Lubuk Ogung untuk dapat mengembangkan budidaya tanaman aren.

\section{METODOLOGI}

Di Kecamatan bandar sei Kijang, baru ada satu desa yaitu Desa Kiyap Jaya yang telah memulai penanaman pohon aren di sela tanaman sawit yang dirintis oleh salah seorang petani sawit. Saat ini terdapat lebih dari 1400 batang aren dari berbagai usia dikebun sawit seluas 20 ha. Diantara tanaman aren tersebut, telah mulai menghasilkan nira aren walau masih terbatas yaitu baru 15 pohon aren.

Desa Lubuk Ogung yang bersebelahan dengan Desa Kiyap Jaya sangat berpotensi untuk mendukung budidaya aren. Target kegiatan adalah tersedianya bibit tanaman aren yang bernilai ekonomis yang dapat dijual kepada masyarakat yang ingin membudidayakan aren atau diatanam sendiri di lahan pekarangan maupun lahan perkebunan yang dimiliki.

Sasaran dari kegiatan ini adalah masyarakat di di Desa Lubuk Ogung Kecamatan Bandar Sei Kijang Kabupaten Pelalawan yang memiliki lahan perkebunan swadaya ataupun lahan pekarangan dan berminat mengembangkan budidaya tanaman aren.

Metode kegiatan pengabdian dilakukan sebagai berikut: (1) kontak aparat desa dan persiapan materi sesuai kebutuhan masyarakat; (2) persiapan Sumber Daya Manusia (petani) dengan pembentukan 4 kelompok tani aren; (3) persiapan alokasi lahan Desa dan lahan masyarakat; (4) pelatihan teori dan praktek teknis pembibitan dan budidaya tanaman aren dan (5) kegiatan persemaian dan pembenihan dan (6) penanaman bibit aren di lokasi lahan yang telah dipersiapkan.

\section{HASIL DAN PEMBAHASAN}

Potensi Desa Lubuk Ogung

Desa Lubuk Ogung di Kecamatan Bandar Sei Kijang dipilih sebagai lokasi kegiatan pengabdian pada masyarakat karena masyarakat dan aparat desa tersebut memiliki keinginan untuk mengembangkan tanaman aren sebagai tambahan penghasilan terkait kondisi perkebunan kelapa sawit dan karet yang selama ini diandalkan masyarakat saat ini mengalami kelesuan dengan harga jual yang rendah. Masyarakat Desa Lubuk Ogung bersedia menggunakan lahan kebun sawit dan pekarangan mereka untuk menjadi lahan sebagai tempat pelatihan dan pembinaan. Selain itu Aparat Desa juga menyediakan lahan untuk lokasi persemaian dan penanaman bibit aren hasil kegiatan pelatihan.

Desa Lubuk Ogung merupakan salah satu dari 4 desa 1 kelurahan di wilayah Kecamatan Bandar Seikijang, yang 
terletak lebih kurang $5 \mathrm{~km}$ ke arah barat dari Ibukota Kecamatan. Kondisi alam daerah ini terdiri dari dataran rendah yang mempunyai rawa-rawa, dibagian sebelah Selatan yang berhampiran langsung dengan Kecamatan Langgam. Sebagian lahan telah dikelola oleh masyarakat maupun perusahaan untuk dijadikan perkebunan sawit. Di Desa Lubuk Ogung juga terdapat beberapa sungai diantaranya, yaitu: Sungai Baboko dan Sungai Ogung. Sungai tersebut sangat berguna bagi desa Lubuk Ogung untuk mencari ikan dan sumber air bersih untuk keperluan sehari-hari dan juga sebagai sumber air bagi perkebunan kelapa sawit. Desa Lubuk Ogung dekat dengan sungai kampar, lahan pertanian, dan dengan ibukota Kabupaten serta Kecamatan Bandar seikijang yang berbatasan langsung dengan ibu kota Provinsi Riau. Perkebunan masih luas, maka sebagian besar penduduknya bermata pencaharian sebagai perkebunan kelapa sawit dan pedagang.

Dengan lahan yang luas dan sumber air yang potensial, rintisan budidaya aren memiliki potensi besar untuk meningkatkan ekonomi masyarakat desa menuju desa yang mandiri sebagai sentra penanaman aren dan agrowisata.

\section{Pelaksanaan Pelatihan Budidaya Tanaman Aren}

Tahap persiapan yang meliputi: (1) Pengurusan izin/rekomendasi melakukan kegiatan penyuluhan dan pendampingan budidaya aren; (2) Pertemuan antara tim tanggal 1 Agustus 2019 serta persiapan materi, bahan dan peralatan yang dibutuhkan; (3) Kunjungan ke lokasi Desa Lubuk Ogung pada tanggal 10 Agustus 2019 dan berdiskusi dengan kepala Desa Bapak Triyono dan aparat desa serta penentuan jadwal pelaksanaan kegiatan dan (4) Pelaksanaan pelatihan selama dua hari pada tanggal 24-25 Agustus 2019 yang mencakup teori, demo dan praktek pengolahan biji menjadi bibit aren.

Kegiatan pelatihan dilakukan di ruangan pertemuan Desa Lubuk Ogung dengan menyajikan slide dilengkapi foto-foto dan video untuk memotivasi peserta tentang prospek ekonomi tanaman aren. Pelatihan diikuti oleh 29 anggota masyarakat, Kepala Desa Lubuk Ogung Bapak Triyono dan 15 orang aparat desa, serta 8 orang mahasiswa Universitas Riau. Kegiatan dimulai pukul 9 pagi dan berakhir pukul 3.30 sore. Tim Bina Desa LPPM Universitas Riau terdiri dari 6 orang dosen Fakultas Pertanian Universitas Riau bekerjasama dengan staf Dinas Kehutanan Provinsi Riau.

Materi hari pertama mencakup prospek ekonomi tanaman aren beserta variasi produk aren yang dapat dikembangkan. Terutama untuk produk nira segar yang saat ini sangat diminati masyarakat karena beragam khasiat untuk kesehatan. Selain itu juga dipaparkan analisis ekonomi dari penjualan nira segar yang sangat menguntungkan dan dapat ditanam di lahan perkebunan sawit yang telah dimiliki masyarakat ataupun lahan pekarangan sehingga membutuhkan modal yang minimal. Dokumentasi kegiatan ditampilkan pada Gambar 1.

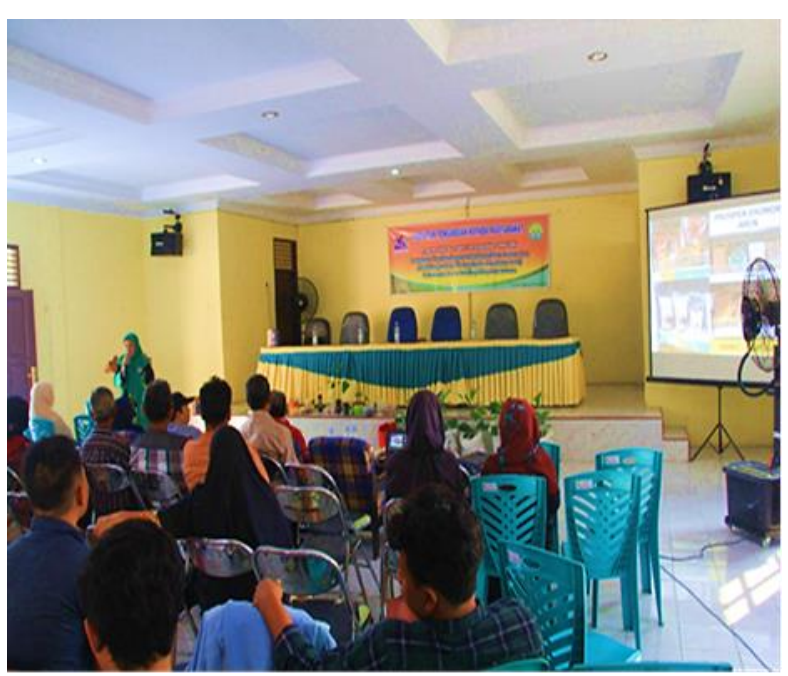

Gambar 1. Kegiatan pelatihan di dalam ruangan Balai Desa Lubuk Ogung.

Motivasi peserta sangat penting agar mampu melihat peluang ekonomis yang sangat tinggi dari hasil olahan tanaman aren. Perhitungan ekonomis sangat penting untuk memotivasi masyarakat agar jelas keuntungan 
yang dapat diperoleh dari usahatani aren. Menurut penyadapan nira aren dapat dimulai setelah tanaman aren berumur 7 hingga 10 tahun ketika perbungaan pertama berkembang (Yusof \& Pebrian, 2016).

Dengan motivasi yang tinggi maka waktu sekitar 7-10 tahun untuk menunggu tanaman aren dapat disadap niranya tidak menyurutkan minat masyarakat untuk membudidayakan aren. Menurut Widayati et al. (2018), tanaman aren sangat produktif karena nira aren dapat disadap setiap hari sehingga sangat membantu perekonomian masyarakat. Selain itu tanaman aren tidak banyak membutuhkan biaya untuk pemupukan dan pemeliharaan yang hal ini sangat berbeda dengan tanaman kelapa sawit yang biaya pemeliharaan rutinnya sangat tinggi.

Berdasarkan pemantauan di Desa Kiyap Jaya yang bersebelahan dengan lokasi pengabdian, rata-rata setiap hari dari 15 pohon aren yang telah berbuah, dihasilkan 200 liter nira dengan harga jual nira murni segar sebesar Rp. 10.000 (untuk nira murni yang tidak direbus) dan Rp. 15.000 (untuk nira murni yang telah direbus sampai mendidih agar tahan lebih lama). Sehingga berdasarkan analisis tersebut, dari 15 pohon aren dapat menghasilkan tambahan pemasukan sebesar minimal Rp. 2.000.000 perhari dan dalam waktu 1 bulan (30 hari) diperoleh pendapatan kotor senilai Rp. 60.000.000. Jumlah ini jauh lebih besar dibandingkan nilai yang dihasilkan kebun sawit. Sebagai pembanding, kebun sawit seluas 20 ha dengan total produksi kotor 50 ton perbulan, dan harga jual tandan buah segar sawit per kilogram saat ini ditingkat produsen (petani) sebesar Rp. 900 dapat dihasilkan sebesar Rp. 45.000.000. Hasil dari kelapa sawit ini lebih rendah dibandingkan nilai jual nira murni dari 15 batang aren.

Materi hari kedua terdiri dari karakter tanaman aren yang terdiri dari aren genjah dan aren dalam. Jenis aren yang dikembangkan sangat penting karena akan menentukan produktivitas tanaman yaitu jumlah nira yang dapat disadap setiap harinya. Bibit unggul dapat menghasilkan pohon nira dengan produksi 10-20 liter nira setiap hari. Dipaparkan juga teknis pengolahan dari biji aren menjadi benih aren yang diikuti dengan praktek pengolahan biji aren menjadi benih yang dilakukan secara berkelompok.

Materi dimulai dengan pemaparan proses pengolahan biji aren yang berasal dari buah aren yang tua dimana setiap buah aren mengandung 3 biji aren yang berwarna hitam. Teknologi pengolahan biji aren menjadi benih yang diterapkan pada pengabdian ini menggunakan bahan dan alat yang sangat terjangkau bagi masyarakat yaitu biji buah aren, atonik untuk perangsang pertumbuhan, air, baskom, kantong plastik, kotak kardus bekas dan koran bekas.

Tahapan pengolahan biji aren menjadi bibit disampaikan kepada peserta sebelum dilakukan praktek. Biji aren direndam air semalaman kemudian dicuci dan dipisahkan biji yang busuk atau biji yang sudah bertunas tapi tidak berkembang. Setelah itu biji-biji direndam dengan air yang dicampur atonik selama 15 menit, selanjutnya disusun berlapis secara merata pada kotak kardus yang diberi lapisan plastik kresek dan koran yang dibasahkan, dibuat beberapa lapis biji diselingi lapisan koran basah, kemudian kantong plastik (kresek) diikat erat dan kotak kardus ditutup rapat dan diikat agar biji aren dapat memunculkan apokol dengan adanya kondisi yang lembab dan gelap. Biji dibiarkan dalam kotak kardus selama sekitar 3-4 minggu. Setelah muncul tunas biji yang berwarna putih sepanjang 2-3 cm, biji aren siap untuk dipindahkan ke polybag ukuran kecil yang diisi dengan tanah dan disiram air pada malam sebelum pemindahan. Hal ini untuk mencegah tanah yang terlalu lembab yang dapat menyebabkan tunas biji aren membusuk. 
Menurut Furqoni et al. (2018), teknis budidaya aren yang baik sangat menentukan kualitas dan produktivitas tanaman aren, terutama pada fase pembibitan (nursery). Benih aren yang berkualitas akan tumbuh dengan lebih baik pada saat dipindahkan ke lahan. Dalam pelatihan ini, untuk praktek penyiapan bibit telah disediakan 1 karung biji aren dari jenis unggul yang dibagikan kepada keempat kelompok peserta untuk melakukan praktek dengan bimbingan langsung dari tim pengabdian.

Semua kelompok melakukan persiapan bibit dengan penuh semangat (Gambar 2) sampai semua tahapan dilakukan dan setiap kelompok memiliki satu kotak kardus berisi banyak calon bibit yang akan diperiksa 3-4 minggu setelah kegiatan pelatihan. Untuk pemantauan lanjutan dibentuk grup Whatsapp sebagai sarana komunikasi 4 kelompok tani aren yang telah dibentuk sebagai hasil dari kegiatan pelatihan agribisnis aren ini.

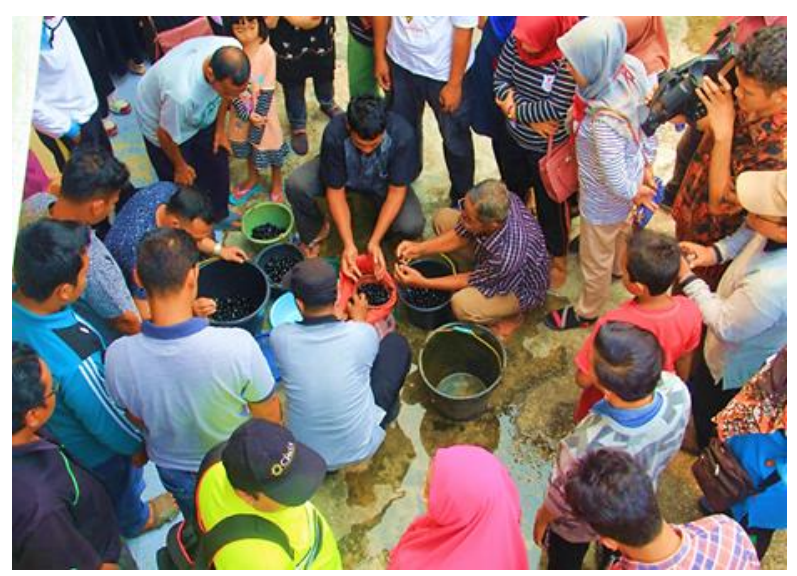

Gambar 2. Peserta mengolah biji aren menjadi calon bibit.

Selain pengolahan bibit dari biji aren yang dilakukan dalam praktek kegiatan, pada akhir kegiatan juga dibagikan bibit aren setinggi $40 \mathrm{~cm}$ yang telah memiliki sekitar 3-4 helai daun dari sumber bibit unggulan nasional asal Bengkulu kepada seluruh peserta kegiatan untuk dapat ditanam di pekarangan masing-masing untuk memudahkan perawatan karena kondisi musim kemarau.
Selanjutnya dilakukan pemantauan proses tumbuhnya biji menjadi benih oleh 4 kelompok tani melalui grup whatsapp selama bulan September 2019 dan pemantauan proses penanaman anakan aren di lahan yang telah disediakan pada bulan November 2019. Dokumentasi benih aren yang telah dihasilkan ditampilkan pada Gambar 3.

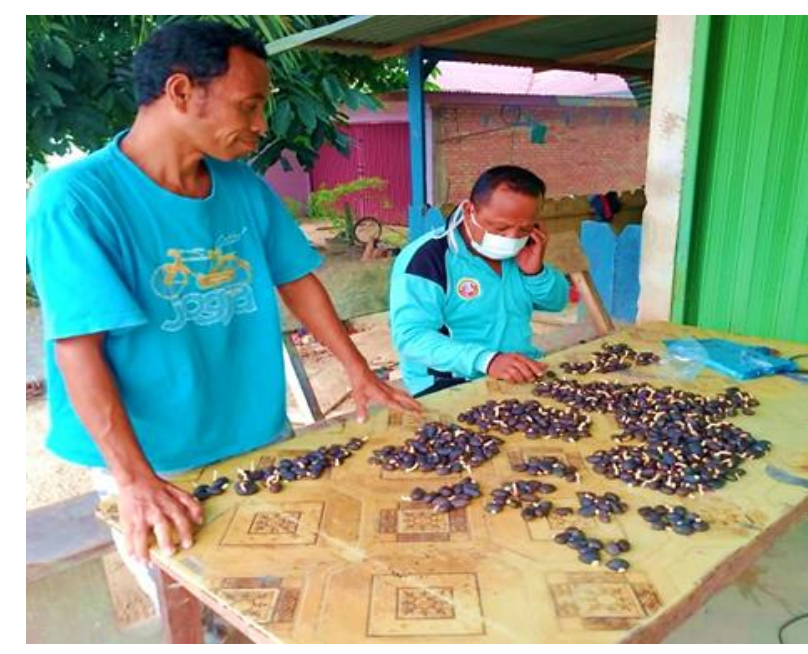

Gambar 3. Benih aren yang diperoleh sebagai hasil pelatihan pembibitan.

\section{Indikator Keberhasilan Kegiatan Pengabdian}

Indikator keberhasilan kegiatan dapat dilihat berdasarkan aspek kelembagaan, aspek kapasitas masyarakat dan aspek nilai ekonomis. Aspek kelembagaan telah berhasil membentuk 4 kelompok tani aren masing-masing 8-10 anggota yang mampu berkoordinasi sampai anakan aren ditanam di lahan yang tersedia.

Aspek kapasitas masyarakat yang meningkat dilihat dari peningkatan pengetahuan tentang prospek dan nilai jual produk aren dan aspek teknis budidaya yang merupakan hasil dari kegiatan pelatihan secara teori dan praktek di lapangan.

Aspek nilai ekonomis dilihat dari produksi anakan aren yang dihasilkan dari kegiatan ini. Pemantauan proses pembenihan aren dilakukan terhadap keempat kelompok tani. Dari 1 karung biji aren unggul yang diproses dengan teknologi pembenihan saat pelatihan, 
dimana tiap kelompok mendapat sekitar 600 biji aren, setelah 1 bulan seluruh kelompok berhasil meperoleh biji aren yang telah bertunas (benih aren) sekitar 500 benih. Maka total benih yang disemai berjumlah sekitar 2000 benih untuk keempat kelompok tani. Setelah berkembang di dalam polybag maka akan diperoleh 2000 anakan aren yang bernilai ekonomis sekitar Rp 10.000 per anakan dengan total nilai Rp 20.000.000.

\section{KESIMPULAN}

Sebagai sentra perkebunan sawit di Kabupaten Pelalawan, masyarakat di Desa Lubuk Ogung memiliki potensi lahan untuk penanaman aren secara monokutur maupun tumpangsari (mix-cropping). Teknologi budidaya aren mudah dilakukan dan dapat dilakukan oleh masyarakat sehingga tidak tergantung pada tanaman aren liar. Teknologi pembibitan dapat menghasilkan bibit aren yang bernilai ekonomis dan membantu pengembangan Lubuk Ogung sebagai sentra aren di masa mendatang. Untuk kegiatan selanjutnya disarankan untuk membangun rumah bibit permanen dan sertifikasi bibit aren.

\section{UCAPAN TERIMA KASIH}

Terima kasih disampaikan kepada Bapak Muhammadun, S.Hut. M.Si dan Bapak Dr. Slamet Wahyudi, S.Pd, M.Si atas dukungannya dalam pelaksanaan kegiatan pengabdian serta Kepala Desa Lubuk Ogung Bapak Triyono dan segenap perangkat Desa Lubuk Ogung atas kerjasamanya dalam kegiatan pengabdian.

\section{REFERENSI}

Alam, S., Baco, D. 2004. Peluang Pengembangan dan Pemanfaatan Tanaman Aren di Sulawesi Selatan (Aspek Tinjauan: Agroindustri dan Konservasi). In Prosiding Seminar Nasional Pengembangan Tanaman Aren. 9 Juni 2004.
Tondano: Balai Penelitian Tanaman Kelapa dan Palma Lain.

Azhar, I., Risnasari, I., Muhdi, Srena, M.F., Riswan. The Utilization of Sugar Palm (Arenga pinnata) by The People Around Batang Gadis Nasional Park Area. IOP Conference Series: Earth and Environmental Science. 35:012016. https://doi.org/10.1088/17551315/305/1/012016

Bernhard, M.R. 2007. Teknik Budidaya Dan Rehabilitasi Tanaman Aren. Buletin Palma. 33:67-77. http://dx.doi.org/10.21082/bp.v0n33.2007.67 $-77$

Efendi, D.S. 2010. Prospek Pengembangan Tanaman Aren (Arenga pinnata Merr) Mendukung Kebutuhan Bioetanol di Indonesia. Perspektif. 9(1):36-46. http://dx.doi.org/10.21082/p.v9n1.2010.\%25 $\mathrm{p}$

Fatah, A., Sutejo, H. 2015. Tinjauan Keragaan Tanaman Aren (Arrenga pinnata Merr) Di Kabupaten Kutai Barat (Perspektif Tinjauan Pemanfaatan Lahan Terdegradasi di Kabupaten Kutai Barat). Agrifor: Jurnal Ilmu Pertanian dan Kehutanan. 14(1):1-14. https://doi.org/10.31293/af.v14i1.1096

Febriyanti, N., Hikmat, A., Zuhud, E.A.M. 2017. The Ethnobotany and Potential of Sugar Palm (Arenga pinnata Merr.) on The Kasepuhan Pasir Eurih Community, Sindanglaya Village, Lebak Regency, Banten. Media Konservasi. 22(2):171-180. https://doi.org/10.29244/medkon.22.2.171180

Furqoni, H., Junaedi, A., Wachjar, A., Yamamoto, Y. 2018. Growth responses of sugar palm (Arenga pinnata (Wurmb.) Merr.) Seedlings to different shading levels. Tropical Agriculture Development. $\quad$ 62(2):55-59. https://doi.org/10.11248/jsta.62.55

Mariati, R. 2013. Potensi Produksi Dan Prospek Pengembangan Tanaman Aren (Arenga pinnata Merr) Di Kalimantan Timur. Agrifor: Jurnal Ilmu Pertanian dan Kehutanan. 12(2):196205. https://doi.org/10.31293/af.v12i2.352

Pohan, M. 2015. Dampak Penurunan Harga Sawit Terhadap Kesejahteraan Petani Sawit Di Pantai Timur Sumatera Utara. Ekonomikawan: 
Jurnal Ilmu Ekonomi dan Studi Pembangunan. 15(2):113-129.

https://doi.org/10.30596/ekonomikawan.v1 5i2.1036

Tenda, E.T., Pandin, D.S., Maskromo, I. 2011. Potensi Pengembangan Aren Genjah Kutim. In Prosiding Seminar Nasional Inovasi Teknologi Perkebunan (ENIP) 2011. Bogor: Pusat Penelitian dan Pengembangan Perkebunan.

Tenda, E.T., Maskromo, I., Miftahorachman, M. 2008. Karakteristik Empat Aksesi Baru Aren (Arenga pinnata Merr) Dari Kalimantan Selatan. Buletin Palma. 35:1-11. http://dx.doi.org/10.21082/bp.v0n35.2008.\% $25 \mathrm{p}$

Widayati, W., Rianse, U., Hanafi, H. Abdullah, W.G. 2018. Empowerment Model of Aren (Arenga Pinnata (Wurmb) Merr) Farmer Through Their Interaction with The Environment. International Journal of Scientific \& Technology Research. 7(7):154-159.

Yusof, Z., Pebrian, D.E. 2016. Analysis of human energy expenditure in harvesting sugar palm (Arenga Pinnata Merr) in Malaysia. Agricultural Engineering International: CIGR Journal. 18(1):149-157. 